\title{
Evolution of particulate matter burden in built-up areas of the Marche Region, Italy: a case study
}

\author{
S. Carletti ${ }^{1}$, G. Di Nicola ${ }^{1}$, G. Passerini ${ }^{1}$ \& U. Rizza ${ }^{2}$ \\ ${ }^{I}$ Department of Industrial Engineering and Mathematical Sciences, \\ Marche Polytechnic University, Italy \\ ${ }^{2}$ National Research Council, ISAC Lecce, Italy
}

\begin{abstract}
Marche Region is a complex valley-coastal area in central Italy comprising valleys, hills, highly populated areas and industrial districts. During the past fifty years (namely from 1954 to 2010) the built-up area has almost tripled no way proportional to the increase of the resident population $(+16 \%)$. In the same time span, airborne emissions have dramatically changed. Emissions from industrial facilities decreased due to the use of Best Available Techniques and the deindustrialization while small and/or mobile sources have become the most important players. This led to a significant deterioration of air quality in the cities of the Marche Region, especially due to road traffic and residential heating. For the new types of sources, emission estimate is the only way to assess local impact. The aim of this paper is to understand why the particulate matter concentrations in urban areas of the Marche Region are often above the legal limits, although several emission sources have decreased. To achieve reliable modelling, we applied two very different air quality models: CALPUFF and CAMx. CALPUFF is a non-steady-state puff dispersion modelling system while CAMx is an Eulerian photochemical model, able to estimate both primary and secondary particulate matter. CALPUFF results are useful to evaluate the concentration of primary particulate matter from the main industrial activities, and their contribution related to the total measured in the environmental monitoring unit. These values have been compared with the results of CAMx simulation which considers all the emissions allocated in a regular grid, so it is possible to assess the contribution of non-point sources such as urban traffic, residential heating and natural emissions. Keywords: built-up area, CALPUFF, CAMx, particulate matter.
\end{abstract}




\section{Introduction}

Environmental assessment has never been easy but, during past two or three decades, the assessment of airborne pollutant impact has turned into a nightmare. In fact, not only regulations and modelling has become more and more complex, but all of a sudden, researchers and stakeholders have seen pollutant emissions evolve from monolithic, easy-to-monitor, sources to a plethora of small, pernicious sources, most of them in continuous movement. Up to 50s, the main almost sole - pollution source was represented by a number of stacks puffing out the heavy smoke of factories and power stations. A less significant role was played by heating systems and small furnaces that often burned coal or bunker or heavy oil. From late 50s, an enormous effort to reduce air pollution at least in densely populated areas started and focused on both the reduction of emissions and on the relocation of massively polluting factories and power stations. In particular, clever stakeholders (of the time) in the UK made companies and power stations move from London and some other major industrial cities following a series of pollution episodes that left thousands dead and let someone to mint the (in)famous neologism "smog". This word, from a certain point of view, can be regarded as a somewhat bridge between science divulgation and phenomenological appreciation. As everybody knows, "smog" comes from the syneresis of the words smoke and fog. Thus, it represents a first effort to communicate the experimental evidence that air pollution depends both on pollutant emissions and on meteorological conditions. In particular, we know that airborne pollutants interact to form PM10 (Particulate Matter smaller than 10 microns in diameter). PM10 is the term used for a potentially toxic mixture of solid particles and liquid droplets suspended in the air [1]. The EU daily mean limit value set for the protection of human health is $50 \mu \mathrm{g} / \mathrm{m}^{3}$, not be exceeded more than 35 days a calendar year. Furthermore, the annual mean must not exceed $40 \mu \mathrm{g} / \mathrm{m}^{3}$. PM10 are a component of a larger category of pollutants named Total Suspended Particulate (TSP) or simply Particulate matter (PM). PM is composed by a plethora of substances going from heavily poisonous metals to nonthreatening marine aerosol. A part of PM suspended in air is emitted directly from pollutant sources while another part materialises into the atmosphere following chemical reactions between "precursors".

During past fifty years (namely from 1954 to 2010) the built-up area within Marche Region has almost tripled no way proportional to the increase of the resident population $(+16 \%)$. Figure 1 shows the performance of population increase and land use increase. In the same time span, airborne emissions have dramatically changed. Emissions from industrial facilities decreased due to the use of Best Available Techniques and the deindustrialization while small and/or mobile sources have become the most important players. This led to a significant deterioration of air quality in the cities of the Marche Region, especially due to road traffic and residential heating. For the new types of sources, emission estimate is the only way to assess the true local impact. Figure 2 shows PM10 concentrations recorded at the monitoring station of "Ancona-Cittadella", which 
is a suburban station set to become the official regulatory station for all the Marche Region.

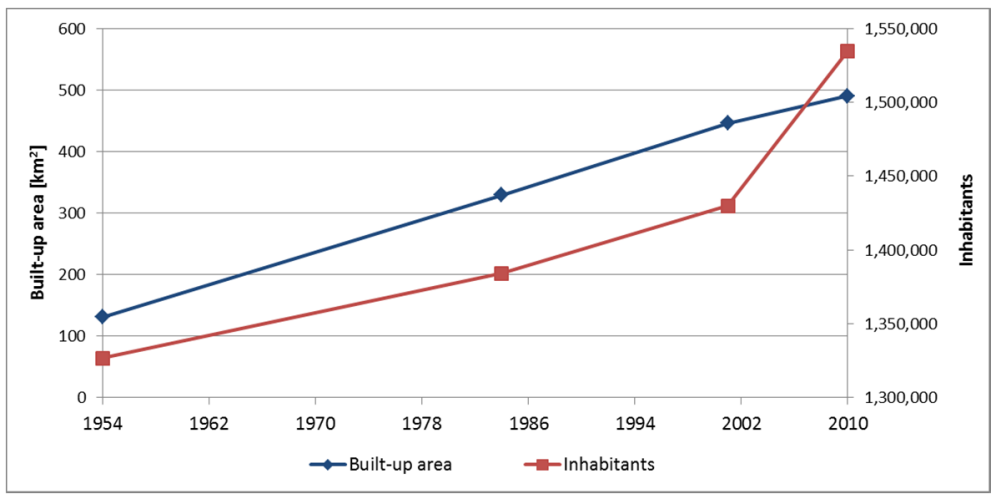

Figure 1: Urban commercial and industrial areas (left hand scale) have almost tripled in the past 50 years while resident population (right hand scale) has increased by only $19 \%$.

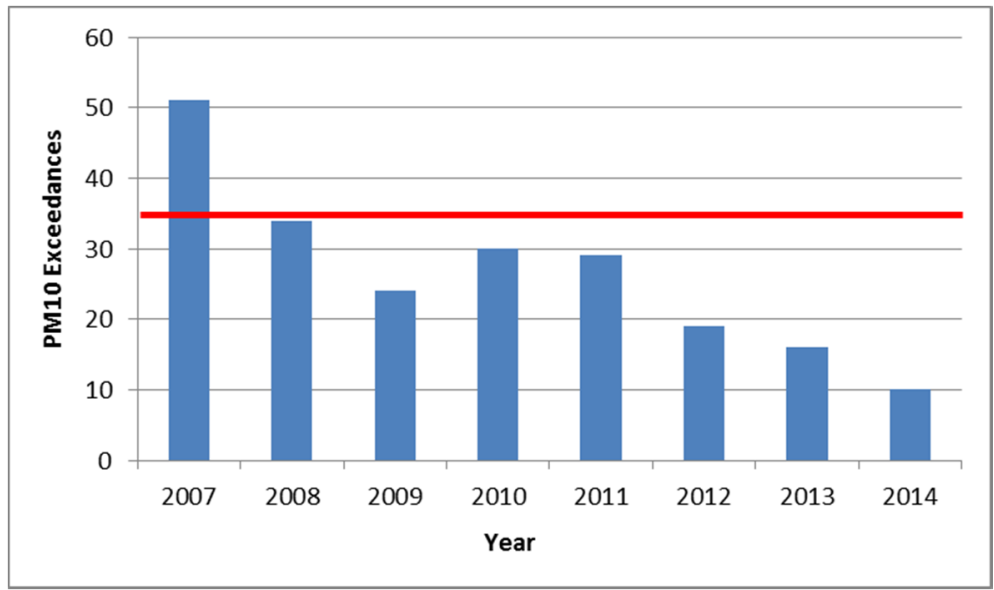

Figure 2: Number of yearly pollution episodes related to PM10 and recorded at "Ancona Cittadella" monitoring station. The station is to become the official regulatory station for all the Marche Region. The red line shows the legal limit.

\section{Modeling system}

In a somewhat famous quote, Daly and Zannetti wrote: "one of the first challenges in the history of air pollution modeling was the understanding of the diffusion properties of plumes emitted from large industrial stacks" [2]. The authors remind 
that the first plume models were conceived during the 30s. Although different types of models today exist to accomplish such objectives, Gaussian models are still widely used for regulatory purposes. These kinds of models were applied for the main purpose of calculating the maximum ground level impact of plumes and the distance of maximum impact from the source. The basic Gaussian diffusion equation assumes that atmospheric stability and all other meteorological parameters are uniform and constant throughout the layer into which the pollutants are discharged, and in particular that wind speed and direction are uniform and constant in the domain.

After years of ISC and ISC like models, during 90s CALPUFF set a new standard for regulatory modelling being a non-steady-state Lagrangian puff dispersion model. The advantage of this model over a Gaussian-based model is that is can realistically simulate the transport of substances in calm, stagnant conditions, complex terrain, and coastal regions with sea/land breezes. In Lagrangian modeling, emissions are seen as assemblies of air parcels (or "puffs"). Each puff is traced by the model along its trajectory, and is assumed to keep its identity during its path. The CALPUFF Modeling System includes three main components: CALMET, a meteorological model that develops hourly wind and temperature fields on a three-dimensional gridded modeling domain, CALPUFF, the core model, and CALPOST that is used to process the results [3].

CAMx (Comprehensive Air quality Model with eXtensions) is an Eulerian photochemical dispersion model that allows an integrated "one-atmosphere" assessment of gaseous and particulate air pollution (ozone, PM2.5, PM10, air toxics, mercury) over many scales ranging from sub-urban to continental. CAMx simulates the emission, dispersion, chemical reaction, and removal of pollutants in the troposphere by solving the pollutant continuity equation for each chemical species on a system of nested three-dimensional grids [4]. The Eulerian continuity equation describes the time dependency of the average species concentration within each grid-cell volume as a sum of all of the physical and chemical processes operating on that volume.

In Eulerian modeling, the area under investigation is divided into grid cells, by means of somewhat meridians and parallels in vertical direction and horizontal direction. Photochemical air quality models have become widely recognized and routinely utilized tools for regulatory analysis, to simulate the fluctuations of pollutant concentrations using a set of mathematical equations characterizing the chemical and physical processes in the atmosphere. These models are applied at multiple spatial scales from local, regional, national, and global.

\section{Point source scenario}

We applied the CALPUFF Modeling System to estimate the concentrations of PM10 from the main point sources of Marche Region. Namely, only Combustion in Power Plants and Production Processes (Sector '01' and Sector '04' according to Corinair/SNAP97 nomenclature) were included. We opted for this scenario since CALPUFF shows some weaknesses in dealing with area sources like urban areas and, remarkably with line sources (e.g. highways). To model these latter, the 
main developer of the model suggests (as reported in the manual), to transform them in volumes. Nevertheless, the CALPUFF modelling system can be used to estimate line source (highway) and area source. These types of sources are considered like small points by the model: the original version of the model approximated all area sources using the virtual point source method [3]. Now the model uses some adjustments factors but we preferred to use an Eulerian model, like CAMx, to estimate the PM10 concentrations from area sources.

In 2012, Institute for Environmental Protection and Research Environment Department (ISPRA) has finalised the provincial (NUTS3) inventory at local scale for the years 1990, 1995, 2000, 2005 and 2010 applying a top down approach. Methodologies used for the previous reporting cycle are described in a related publication [6].

All over Italy (Figure 3) as well as in Marche Region (Table 1), PM10 emissions from Sector '01' and Sector ' 04 ' are decreasing.

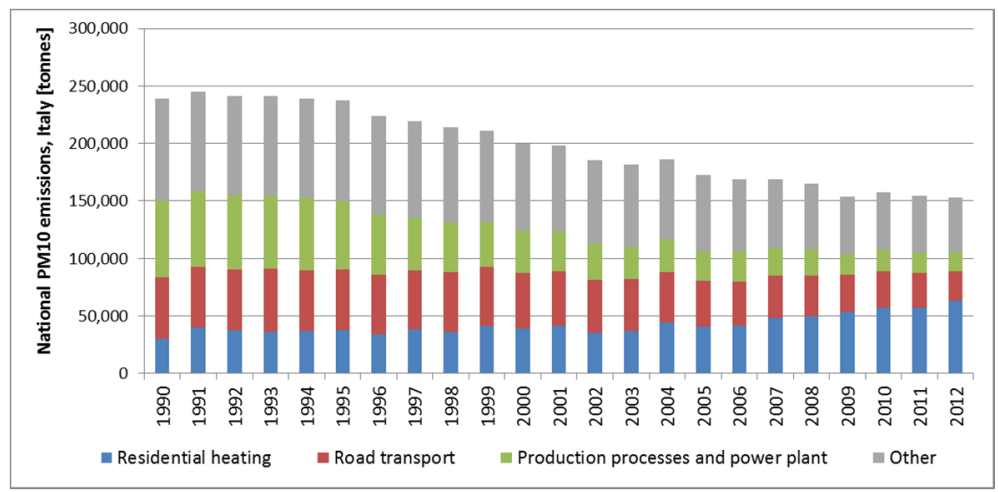

Figure 3: Contribution of Corinair/SNAP97 groups to airborne pollutant emissions of PM10 in Italy [5].

Table 1: Emissions of PM10 from SNAP97 groups 01 and 04 in the Marche Region $[5,6]$, and their weight over the total PM10 regional emissions.

\begin{tabular}{|l|c|c|c|c|c|}
\hline & 1990 & 1995 & 2000 & 2005 & 2010 \\
\hline $\begin{array}{l}\text { Production processes and power } \\
\text { plant (tonnes) }\end{array}$ & 418 & 361 & 338 & 324 & 200 \\
\hline $\begin{array}{l}\% \text { production processes and power } \\
\text { plant to total PM10 emissions }\end{array}$ & $8 \%$ & $7 \%$ & $7 \%$ & $6 \%$ & $4 \%$ \\
\hline
\end{tabular}

Figure 4 shows the main point sources of airborne pollutants (red dots) and urban areas (grey areas) within the Marche boundaries (blue line). All point sources have been assessed, considered and introduced in the model. As for the time-span, our study was performed over one month, namely from January 1 to January 31 of 2012. We chose such period since January represents one of the 
worst months for air pollution in general and pollution episodes. This is especially true for NOx and PM. The results of CALPUFF simulations are reported in Table 2. Each row considers a monitoring station. The first column shows the conventional name of the station, the second column shows the average of all the hourly values monitored during January 2012, and the third column shows the average concentration obtained, over the same period, by CALPUFF. We would stress that all the monitoring units are sub-urban or rural stations, and for this reason, they are not directly influenced by road traffic or industrial plants. The concentrations evaluated by the model are very low compared to the related values measured at stations. This was obvious and expected since we did not include area and line sources and we did not evaluate secondary particulate, resuspension etc. However, this scenario showed that the component of PM10 directly due to plant stack is almost negligible when compared to the experimental evidence. Such evidence supports the results of previous studies obtained by means of the wellknown Gaussian regulatory model AERMOD [7]. In conclusion, we found that to model with acceptable accuracy PM10 environmental impact, it seems unavoidable to use an Eulerian model to estimate the diffusion of all the sources (including area sources and line sources) and to estimate the secondary pollution by means of a photochemical model.

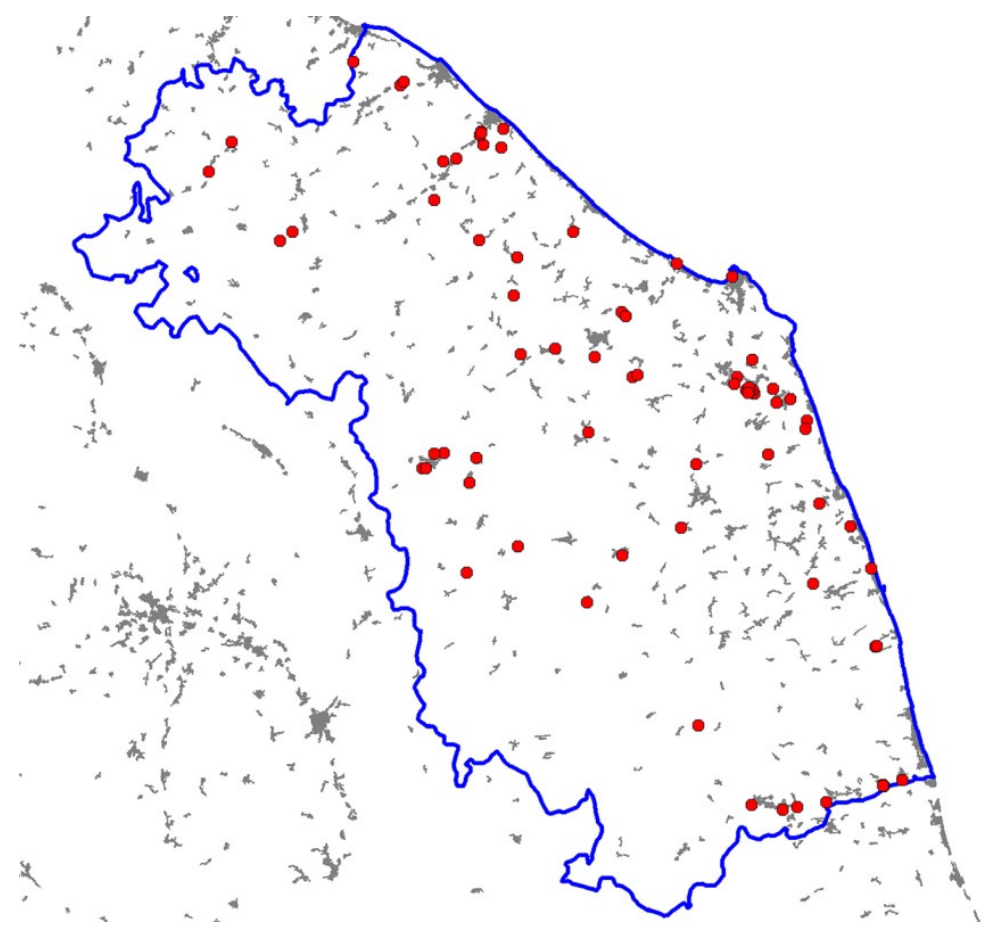

Figure 4: Point sources (red dots), urban areas (grey areas) in Marche Region (boundaries are the blue line). 
Table 2: Monitored and predicted average PM10 concentration (CALPUFF), at “Ancona Cittadella", from January 1 to January 31 of 2012.

\begin{tabular}{|l|c|c|}
\hline Monitoring station & $\begin{array}{c}\text { Average PM10 } \\
\text { concentration }\left(\mu \mathrm{g} / \mathrm{m}^{3}\right)- \\
\text { CALPUFF }\end{array}$ & $\begin{array}{c}\text { Average PM10 } \\
\text { concentration }\left(\mu \mathrm{g} / \mathrm{m}^{3}\right)- \\
\text { Measured value }\end{array}$ \\
\hline "Ancona Cittadella" & 0.69 & 31 \\
\hline "Falconara Scuola" & 1.94 & 45.9 \\
\hline "Jesi" & 0.84 & 46 \\
\hline "Chiaravalle/2" & 0.98 & 39.9 \\
\hline
\end{tabular}

\section{Area source scenario}

Photochemical models simulate the photochemistry occurring hour-by-hour into each grid cell in the modelling domain. Therefore, emission data shall exhibit a comparable level of resolution. Total emissions (e.g., Primary PM, VOC) must be chemically allocated into the chemical classes employed by the model. Additionally, the emissions data must be spatially allocated by grid cell for each hour of the modelling episode [8]. On applying CAMx, such high-resolution emission scenario can be designed and arranged by taking advantage of the flexibility of EPS3 (Emissions Processing System [9]) which provides the user with many options for processing all emissions. Concerning particulate matter assessment, the model is usually applied for a multi-day period during which adverse meteorological conditions result in elevated concentrations. For the present study, we used two grids: a master grid, that covers most of continental Italy, and a nested grid that embraces the Marche region. The temporal period is the same of CALPUFF simulation.

Airborne pollutant emission inventories here applied have been developed based on previous national and European studies. For the sources at European level (outside Italy) we chose inventories by the EMEP Centre on Emission Inventories and Projections [10]. For the sources at national level (all the provinces outside Marche Region), we chose the Italian Emission Inventory 2010 above cited [5]. For the highest resolution inventory (at municipality level within the Marche Region) we performed a top-down disaggregation of the national inventory.

Given the very high degree of details given by municipality level (Figure 5), all the emissions have been added as area sources. This is another reason for running CALPUFF in "point source scenario": the relative weight of point source emissions compared to the total PM10 measured at each monitoring station is around $5 \%$ or less (Table 2 ).

We know for sure that two main emission sources are responsible for most of primary PM pollution in the study area. The two sources are emissions from road transports and emissions from residential heating. For road transports we take into account both highways and urban/suburban road traffic. The emission trend for the Marche Region is reported in Figure 6: the total PM decreased in the past two decades thanks to improved technologies. 


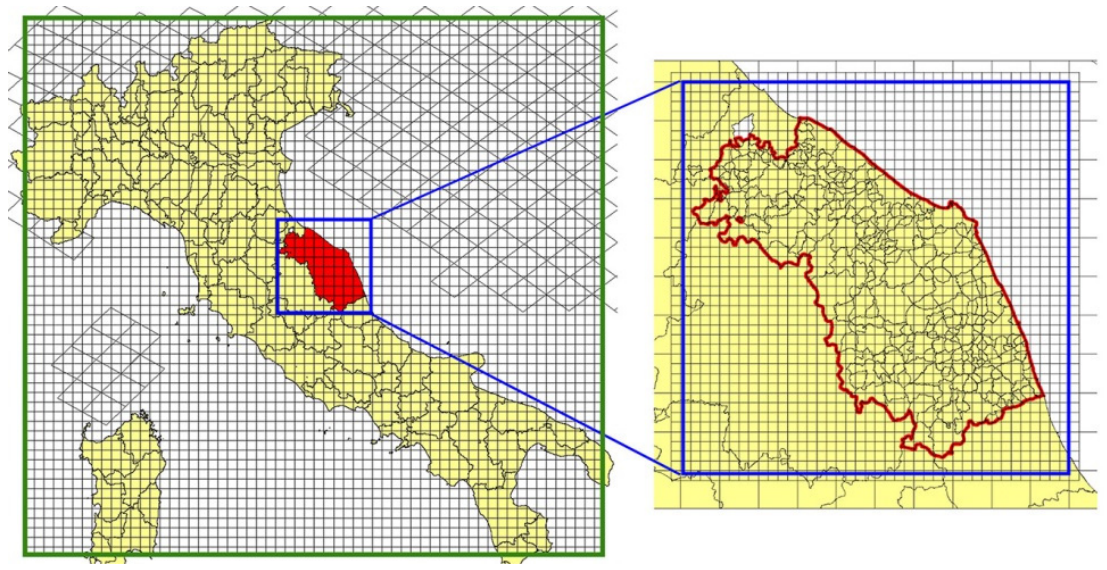

Figure 5: Master grid G1 (green) and nested grid G2 (blue); area sources within Marche Region (boundaries are in red) are the municipality territories.

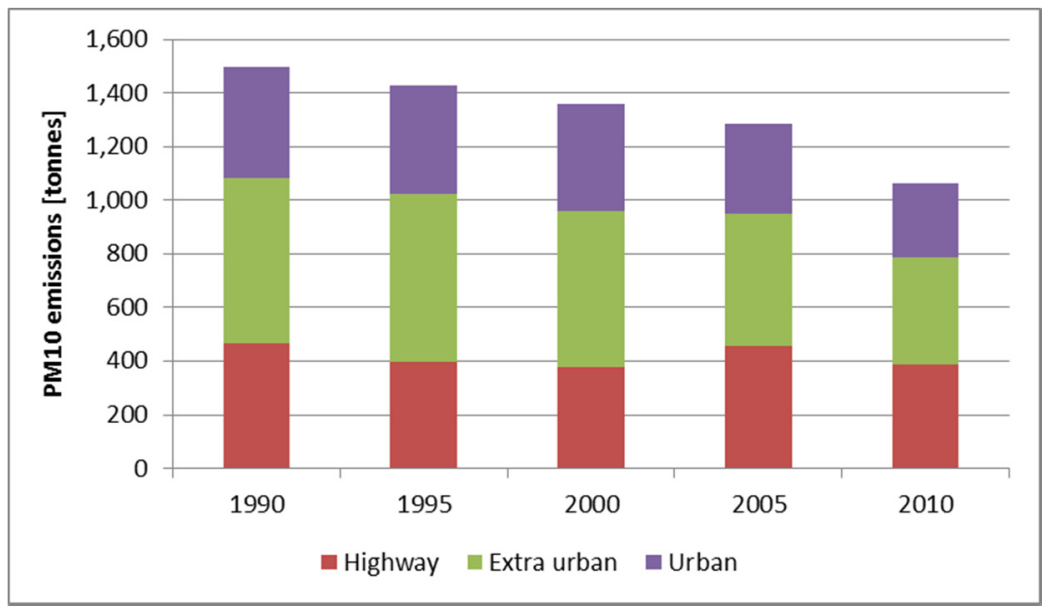

Figure 6: Marche Region emission trend for the Corinair/SNAP97 sector 07: Road Transport.

In Italy and in Marche region, residential heating represents the major source of PM emissions and its estimated rate has increased during past decade both due to a more sophisticated evaluation and from an actual change of the blend of fuels. In fact, PM emissions derive almost entirely from the combustion of biomass, since methane (mostly used) has a very low emission factor while other fossil fuels represent a small fraction of the fuel consumption. However, all residential heating represents a source of precursors of secondary particulate (mostly NOx). Such precursors are emitted by all the heaters and, in this case, those burning methane play a major role. 


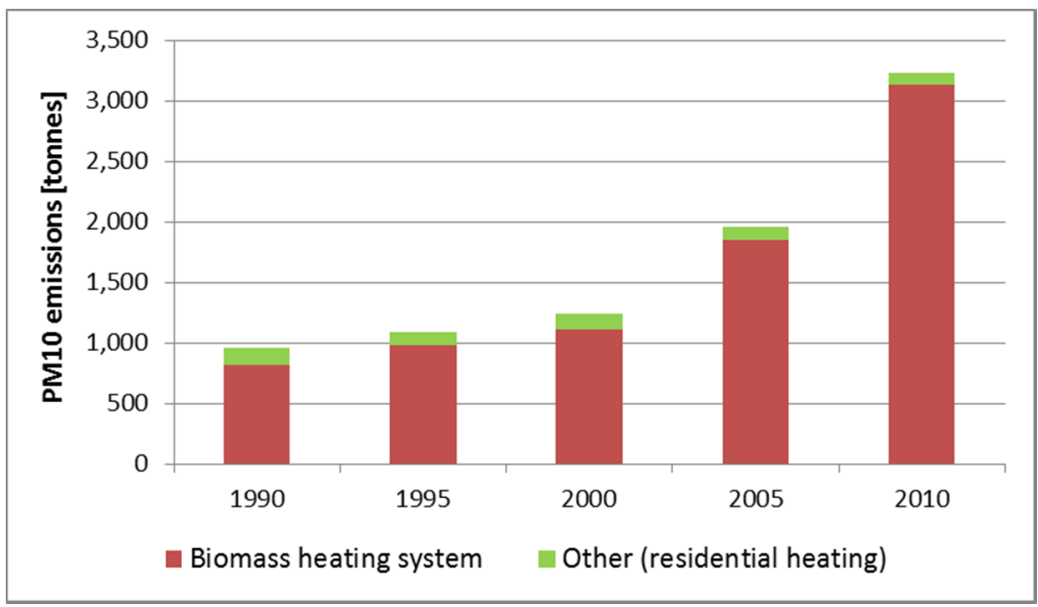

Figure 7: Marche Region emission trend for the main sector 02, according to Corinair/SNAP97 nomenclature.

\section{Results}

Figure 8 and Figure 9 show the results obtained running CAMx with meteorological data evaluated by means of mesoscale meteorological model RAMS [8, 11]. Two main things are evident at a first glance. First, CAMx predicted quite well the behaviour (i.e. the slope in the graph) of particulate matter concentrations during the 31 days of simulation but it systematically underestimated the actual amounts. As a second important remark, CAMx results are more comparable with monitored PM2.5 concentrations than with PM10 concentrations. In fact, the difference between monitored PM10 and PM2.5 is mainly represented by the crustal coarse material and the marine aerosol, which have not been introduced into the model intentionally. Actually, most of pernicious secondary particulate matter is smaller than $2.5 \mu \mathrm{m}$, while coarse components usually are less hazardous to human health (for sure marine aerosol and most crustal matter). Aim of our studies is to assess the amount of toxic pollutants so we can conclude that our results represent exactly our goal.

\section{Source apportionment}

As reported in the CAMx manual [4], "source apportionment for primary PM is relatively simple to obtain because the source-receptor relationships are essentially linear and do not depend on other sources. This assumption breaks down for secondary PM pollutants (sulfate, nitrate, ammonium, secondary organic aerosol)".

Particulate Matter Source Apportionment (PSAT) is a tool embedded in CAMx, that tracks the contributions to each grid cell from emissions source 


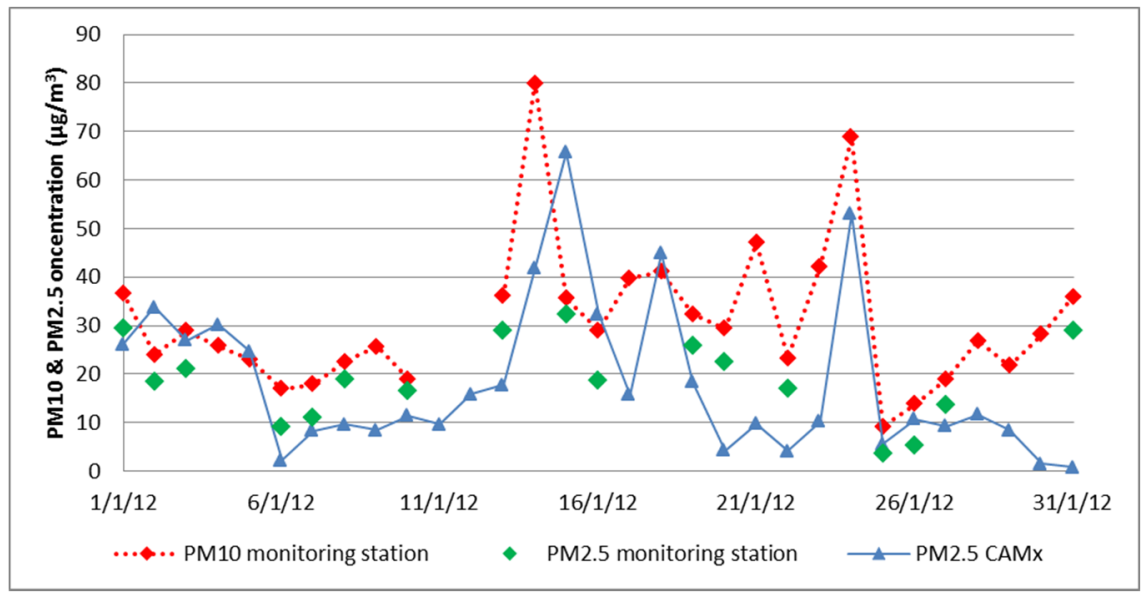

Figure 8: PM10 and PM2.5 average daily concentrations monitored at "Ancona Cittadella" station and predicted by CAMx on the site.

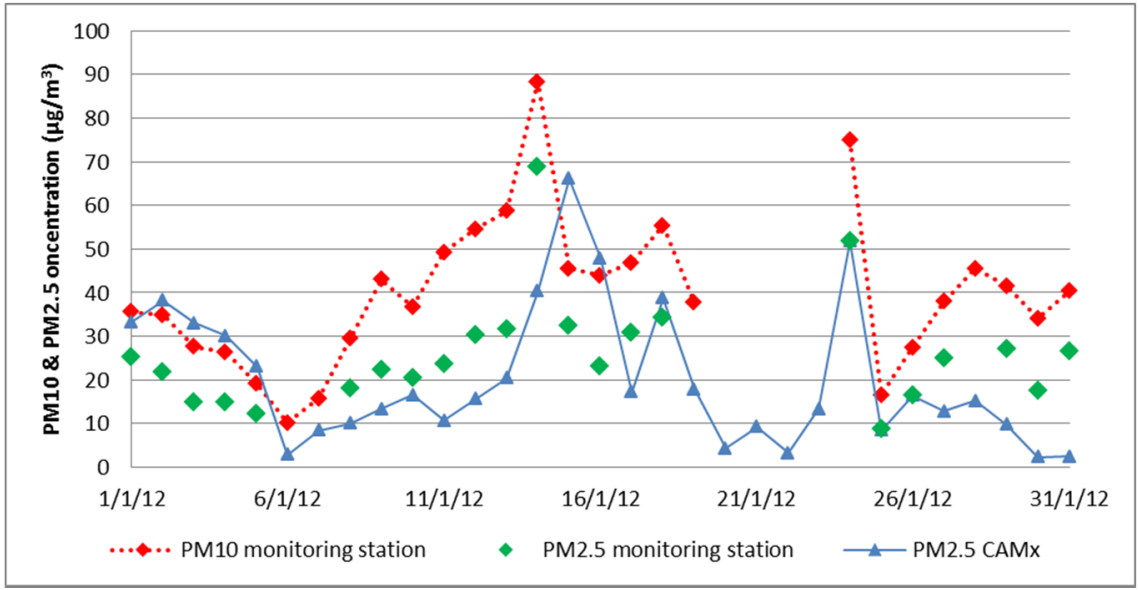

Figure 9: PM10 and PM2.5 average daily concentrations monitored at "Chiaravalle/2" station and predicted by CAMx on the site.

groups, emissions source regions, initial conditions, and boundary conditions through reactive tracer species. PSAT apportions secondary PM species to their corresponding precursor sources. Tracers provide information on the relative importance of transport and chemistry [12]. In this way, since emissions errors are likely to affect some source categories more than others are, through PSAT results it can be interpreted the base-case performance of CAMx model.

We are now tuning PSAT to understand the main contributors to secondary PM10 and preliminary results are very promising. 


\section{Conclusions}

Results of Point Source Scenario show that stacks account for a very small part of total primary PM10 burden. In fact, the emissions of primary PM from main sectors 01 and 04 (Power Plants and Production processes) are very low. For this reason, it is recommended the use of an Eulerian photochemical model, instead of Gaussian model or puff model. However, the contribution of such sectors to the formation of Secondary Particulate has to be assessed by means of PSAT.

From a first analysis of the CAMx results at "Ancona Cittadella", it seems that Primary particulate matter represents about half of the total PM. Thus, it is mandatory to apply models that can estimate the secondary particulate matter. The increase of built-up area favors the accumulation of PM10, both for road transport and for residential heating. A general decrease of air pollution took place in the last years [13] mainly due to the adoption of Best Available Techniques and emission abatements in industrial processes and, above all, due to the adoption of "Euro" standards for new cars, coaches, and trucks. However, the demand to reduce the use of fossil fuels has spread the use of biomass as combustion fuel. The biomass combustion systems burn renewable fuel but, at the present stage, most furnaces and stoves perform uncontrolled or badly controlled combustions that have a serious impact on urban air quality.

Marche Region includes an area that has been claimed "Highly at risk of environmental crisis" due to the presence of a multitude of anthropogenic pollution sources. In recent years, Local Authorities started to monitor vascular diseases within the risky area trying to assess their correlation with long-term exposure to Particulate Matter [7]. The results of CAMx model will be used to assess mortality and morbidity due to the exposure to PM10.

\section{References}

[1] Carletti S., Latini G. \& Passerini G., Air pollution and port operations: a case study and strategies to clean up, The Sustainable City VII, Vol. 1, pp. 391-403, WIT Transactions on Ecology and The Environment, Vol. 155, 2012.

[2] Daly, A. \& Zannetti, P., Air Pollution Modeling - An Overview. Chapter 2 of Ambient Air Pollution, Arab School for Science and Technology (ASST) and EnviroComp Institute, 2007.

[3] Scire, J.S., Strimaitis, D.G. \& Yamartino, R.J., A User Guide for the CALPUFF Dispersion Model, Earth Tech, 2000.

[4] Comprehensive Air Quality Model with Extensions, CAMx User's Guide, Version 5.30, Environ International Corporation, 2010.

[5] Italian Emission Inventory 1990-2011. Informative Inventory Report 2013, Rapporti 178/2013, ISPRA, 2013.

[6] La disaggregazione a livello provinciale dell'inventario nazionale delle emissioni, Anni 1990-1995-2000-2005, Rapporti 92/2009, ISPRA, 2009. 
[7] Latini, G., Passerini, G. \& Principi, F., Evaluation of long-term exposure to pollutants by means of a dispersion model, Environmental, Energy, and Structural Monitoring Systems, IEEE Workshop, 2009.

[8] Carletti, S. \& Passerini G., Tropospheric ozone behaviour as a function of precursor emissions, Environmental Impact II, pp. 3-14, WIT Transactions on Ecology and The Environment, Vol. 181, 201.

[9] Emission Processor User's Guide, Version 3.20. Environ International Corporation, 2010.

[10] Review of emission data reported under the LRTAP Convention and NEC Directive, Inventory Review, CEIP - Centre on Emission Inventories and Projections, 2013.

[11] Cocci Grifoni, R., Magnaterra, L., Passerini, G. \& Tascini, S., Importance of local meteorology in coastal ozone dynamics: a case study, Air Pollution XI, WIT Press, pp. 95-104, 2003.

[12] Yarwood, G., Wilson, G. \& Morris, R., Development of the CAMx particulate source apportionment technology (PSAT), Environ International Corporation, 2005.

[13] Latini, G., Pacetti M. \& Passerini G., Air quality and environmental sustainability: the situation of Ancona city and its district, The Sustainable City VII, Vol. 1, pp. 503-514, WIT Transactions on Ecology and The Environment, Vol. 155, 2012. 